\title{
Highly Optimization Design of Structure Space
}

\author{
Wang Fucheng ${ }^{1 \mathrm{a}}$, Chen Chenyu ${ }^{2 \mathrm{~b}}, \mathrm{Ji}^{\mathrm{jing}}{ }^{3 \mathrm{c}}$
}

${ }^{1}$ August first land reclamation university engineering university Daqing; Heilongjiang,China,163319

${ }^{2}$ Daqing Normal University Physics and electrical engineering information, Daqing; Heilongjiang , China,1637128 $3{ }^{3}$ College of Civil and Architecture Engineering, Northeast Petroleum University, Daqing 163318,China;

afuchengwang@163.com, bccy08190309@163.com, ${ }^{\mathrm{C}} 641244513 @ q q . c o m$

Keywords: structure space, optimization design, highly option, genetic algorithm

\begin{abstract}
The optimization mathematical model for highly optimization is established with the constraints of strength, rigidity, stability and the structural deflection of structure space and solutions are obtained by using the genetic algorithm. A example indicates that the genetic algorithm can be applied in the optimal design of structure space and reliable results can be obtained.
\end{abstract}

\section{Introduction}

Space truss is a sort of extensive space structural form. The structure can be seen at oil servi-ce, stadium, large-scale dining room, marketplace, and so on. Its pole piece arranges according to the certain regulation, and it is a space net structure through the node conjunction. Many space trusses carry out structural function by steel structure. So, there is actual meaning with optimiza-tion to steel structure. According to 《the Space Trusses Design and Construction Rules》(JGJ7-91),this paper study optimization design of space truss structures with the genetic algori-thm.

\section{Built space trusses mathematical model}

Mathematical model of optimization design is mathematical description to engineering problems optimization design, it has three basic elements: design variables, objective function and constraint condition.

\section{Design variables}

Regard Highly of Structure Space as design variables:

$h=[a, b]$

Which: $h$-- Highly of Structure Space ; $a, b--$ constants

\section{Objective function}

Objective function is total weight of space trusses’ member bar

$$
\min W(A)=\sum_{i=1}^{n} r_{i} g l_{i}
$$

Which: W(A)-- total weight of space trusses' member bar, kg

$r_{i}$--linear density of bar, $\mathrm{kg} / \mathrm{m}$; $\quad l_{i}$--length of bar, $\mathrm{m}$

$n$--total numbers of bar, $g$-acceleration of gravity, $9.8 \mathrm{~m} / \mathrm{s}^{2}$

\section{Constraint condition}

Space trusses' member bar is axially loaded members. axially loaded members be control by strengthen and stiffness, axially loaded compression members be control by strengthen, stiffness and stability. So, constraint condition of Optimization Design of Structure Space is:

$$
\left|\frac{N_{i}}{A_{i}}\right| \leq[\sigma]=215 \mathrm{~N} / \mathrm{mm}^{2}
$$




$$
\begin{aligned}
& \lambda=\frac{l_{0}}{i_{i}} \leq[\lambda]=\left\{\begin{array}{l}
180 \\
300 \\
400
\end{array}\right. \text { Tension member of nearby bearing } \\
& \left|\frac{N}{\varphi A_{i}}\right| \leq[\sigma]=215 \mathrm{~N} / \mathrm{mm}^{2}
\end{aligned}
$$

$A_{i} \geq A_{\text {min }}$

Which: $N_{i}$-- axial force of bar, $\mathrm{N}$; $A_{i}$--sectional area of bar, m2; $[\sigma]$--allowable stress of bar, $\mathrm{N} / \mathrm{mm} 2$;

$\lambda$--slenderness ratio of bar; $l_{0}$--effective length of bar, $\mathrm{m}$; $i_{i}$--radius of gyration of bar, $\mathrm{m}$;

$[\lambda]$-- allowable slenderness ratio of bar; $N$-- axial force ofcompression bar, $\mathrm{N} ; \varphi$--stability

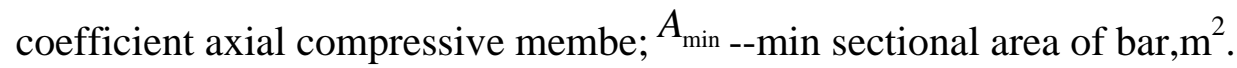

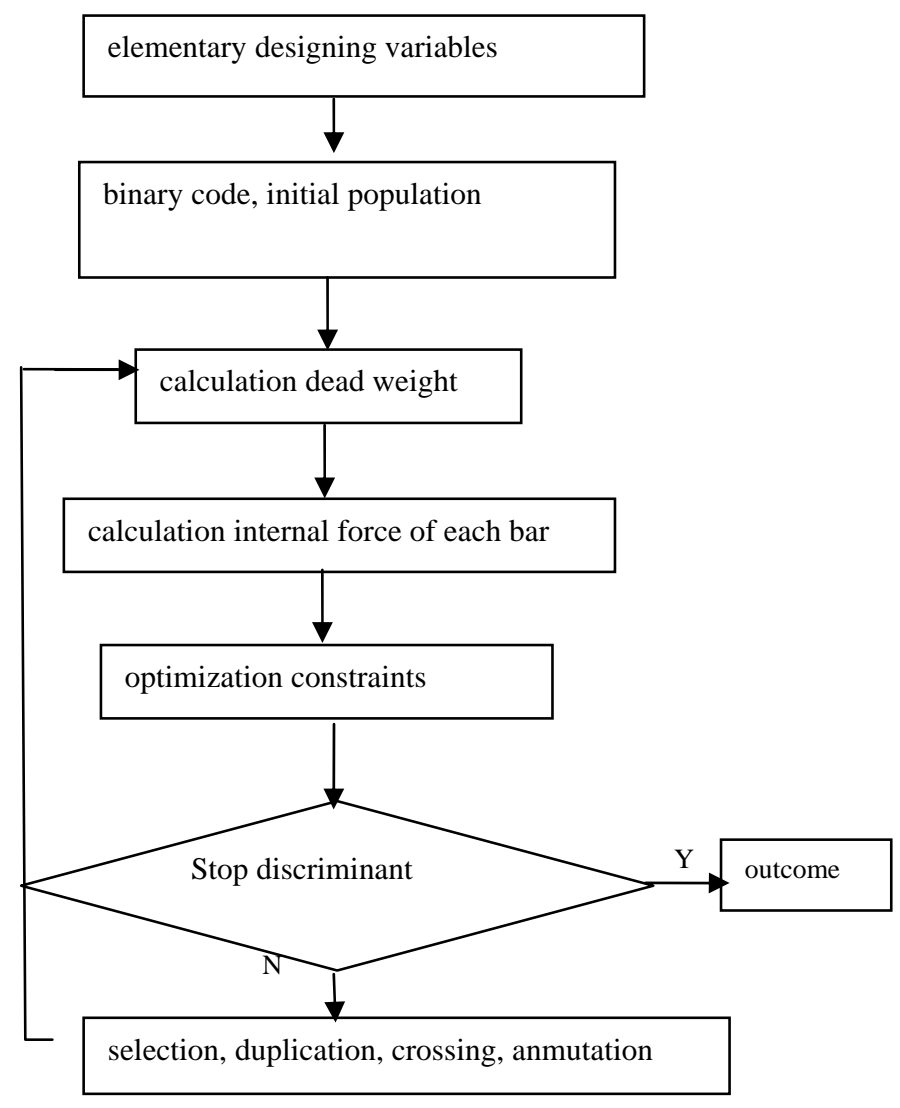

Fig 1 GA Process chart

\section{Structure analysis}

Structure Space must be mechanical analysis in the optimal procedure of the structures. This paper used space truss displacement method to calculation the internal force . This method consider joints in space truss three linear displacement as unknown quantity, suitable for all kinds of structure space, and considered different plane shape, different boundary conditions and supporting way, bear any loads and effect. The paper use space truss displacement method to calculate internal force of Structure Space the relation between elemental rod end force and nodal displacement in the whole coordinate:

$$
\{\bar{F}\}^{e}=[k]^{e} \cdot\{\bar{\delta}\}^{e}
$$

Whole stiffness equation can get by node equilibrium conditions and deformation compatibility condition. 
$P=K \cdot \delta$

Supporting the introduction of boundary conditions, on the stiffness of the overall equation available structure of the node displacement vector can be obtained and then the structure of the unit under the axial force.

\section{Description of genetic algorithm}

The GA has a strong search capability in the large search space. Genetic Algorithms are search algorithms based on of natural evolution processing including selection, mutation and crossover operations on the genes of individuals or potential solutions.

GA is based on the principle of the theory of evolution developed a widely used and efficient method of random search and optimization. In engineering, computer science, management science and social science fields, in a very broad application.

Genetic algorithms, including the ealization of the process of encoding, the initial group, fitness, choice of cross, the basic genetic mutation operation.

Fitness: According to the biological evolution "survival of the fittest" principle, the needs of each individual's ability to adapt to the environment compared in order to introduce the concept of fitness, fitness is the value of genetic algorithm in the evolution of groups used the only information it How to copy the string gives quantitative description. Fitness function by calculating the value of the individual's fitness, to compare the individual's fitness.

Genetic Operation: Genetic population operations for the individual to choose to copy the string, the crossover and mutation, and so on to deal with the aim of a new individual, constitute a new species. This process is the biological evolution of imitation. The overall population have a fitness than a generation ago, after several generations of iteration, the population has been continuously optimized, the process is similar to the natural world of biological evolution. Measure the fitness of individual parameters is the fitness function.

Genetic Operation:Genetic population operations for the individual to choose to copy the string, the crossover and mutation, and so on to deal with the aim of a new individual, constitute a new species. This process is the biological evolution of imitation. The overall population have a fitness than a generation ago, after several generations of iteration, the population has been continuously optimized, the process is similar to the natural world of biological evolution. Measure the fitness of individual parameters is the fitness function. Termination of the guidelines: Termination of the guidelines refer to the circumstances under which that algorithm to find the optimal solution, which can terminate the algorithm, to be the optimal solution.

The use of Matlab software program, developed a network to solve the structure of internal force and displacement of the finite element program, the preparation of three genetic operator, on this basis, the preparation of the grid structure of the genetic algorithm procedure, carried out a grid structure Design of optimization calculation. Figure 1 for the genetic algorithm flow chart

\section{Examples and analysis of the results Conclusion}

Simply supported around the pyramid is put grid, Grid size is $3.0 \mathrm{~m}$, Grid number is $11 \times 11$, Materials is Q235, Young's modulus is $E=2.06 \times 105 \mathrm{~N} / \mathrm{mm}^{2}$, Network load for the dead load standards is $30 \mathrm{Kg} / \mathrm{m}^{2}$,Living standards set value is $50 \mathrm{Kg} / \mathrm{m}^{2}$, optimize the results of the literature [1] results shown in Table 1. 


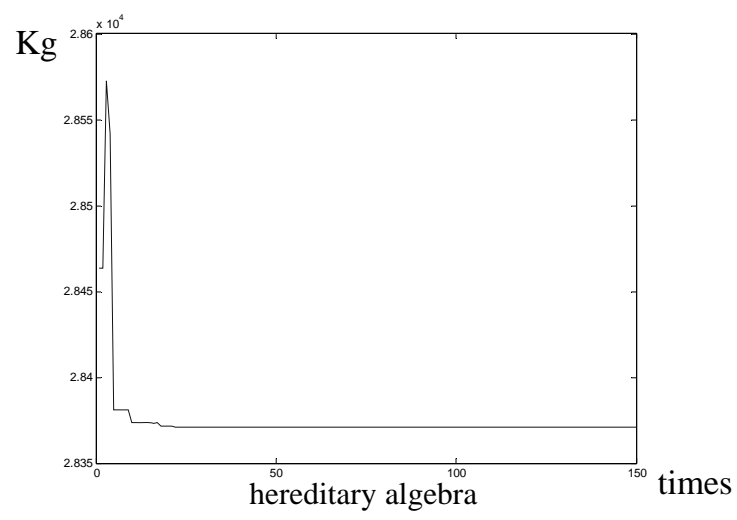

Fig $233 \mathrm{~m} \times 33 \mathrm{~m}$ optimization process

Tab $133 \mathrm{~m} \times 33 \mathrm{~m}$ Highly optimized results comparative

\begin{tabular}{|c|c|c|c|}
\hline & Mass(kg) & Height of space trusses(m) & Rise-to-span ratio \\
\hline Before the optimization & 32126 & 1.8 & 0.055 \\
\hline After the optimization & 28371 & 1.7 & 0.052 \\
\hline optimum ratio & $11.69 \%$ & $5.5 \%$ & $5.5 \%$ \\
\hline
\end{tabular}

Simply supported around the pyramid is put grid, Grid size is $3.0 \mathrm{~m}$, Grid number is $12 \times 12$, Materials is Q235, Young's modulus

$E=2.06 \times 105 \mathrm{~N} / \mathrm{mm}^{2}$, Network load for the dead load standards is $30 \mathrm{Kg} / \mathrm{m}^{2}$, Living standards set value is $50 \mathrm{Kg} / \mathrm{m}^{2}$, optimize the results of the literature [1] results shown in Table 2.

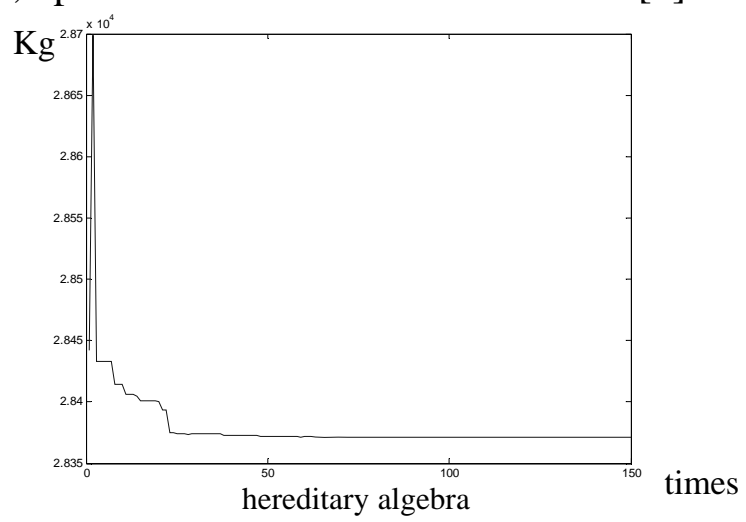

Fig $336 \mathrm{~m} \times 36 \mathrm{~m}$ optimization process

Tab $236 \mathrm{~m} \times 36 \mathrm{~m}$ Highly optimized results comparative

\begin{tabular}{|c|c|c|c|}
\hline & Mass(kg) & $\begin{array}{c}\text { Height of space } \\
\text { trusses(m) }\end{array}$ & Rise-to-span ratio \\
\hline Before the optimization & 33696 & 2.7 & 0.075 \\
\hline After the optimization & 28398 & 2.5 & 0.069 \\
\hline optimum ratio & $15.72 \%$ & $7.41 \%$ & $8.0 \%$ \\
\hline
\end{tabular}

\section{Conclusion}

1) Using genetic algorithms to solve the structure of a high degree of network optimization for different boundary conditions, support a different way, as well as to bear the load of different grid structure.

2) Using genetic algorithms to optimize network structure of high global optimization can be carried out to avoid the results of a local optimal solution;

3) Using genetic algorithms to optimize network structure height, to save steel, reliable and can be used in actual projects.

\section{Acknowledgements}

This work was financially supported by Youth Foundation of Daqing Normal University research 
project(Serial number:09ZQ08)

\section{Reference}

[1]Qian Lingxi. Optimum design of engineering structures[M]. Beijing: Water Resources and Hydropower Press, 1983

[2]Liu Xiliang, Han Qinghua. The design and construction of lattice structure[M], Tianjing: Tianjing university press 2004.4

[3]ZHANG Feizhou,CAO Xuejun,YANG Dongkai, Intelligent Scheduling of Public Traffic Vehicles Based on a Hybrid Genetic Algorithm, TSINGHUA SCIENCE AND TECHNOLOGY, Volume 13,Number 5,October 2008

[4] Iwan W.D. and Gates N.C. .The Effective Period and Damping of a Class of Hysteretic Structures [J]. Earthquake Engineering and Structural Dynamics. 1979.7. pp199-211

[5] Shahram Taghavi and Eduardo Miranda Approximate Floor Acceleration Demands in Multistory Buildings,(I-II)[J]:Applications. Journal of Structural Engineering, 2005, 3 